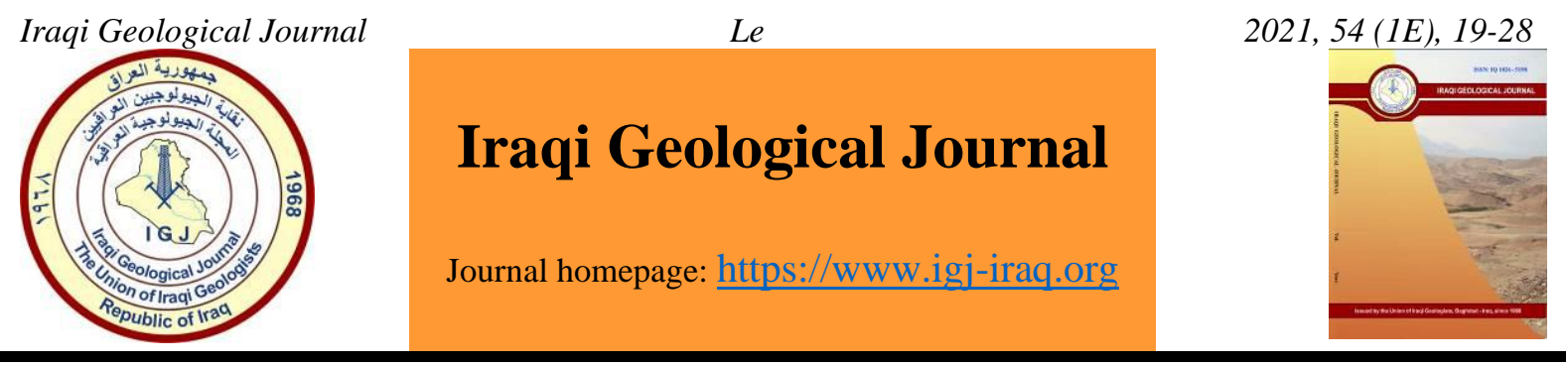

\title{
Characterization and Distribution of Cenozoic Polygonal Fault: Case Studies in West Africa and Vietnam Continental Margins
}

\author{
Anh Ngoc Le ${ }^{1, *}$ \\ ${ }^{1}$ Hanoi University of Mining and Geology, Vietnam \\ *Correspondence: lengocanh@humg.edu.vn \\ Received: 28 January 2021; Accepted: 19 March 2021; Published: 31 May 2021
}

\begin{abstract}
The Cenozoic sequence of offshore Cameroon and Vietnam has been analysed based on newly $1500 \mathrm{~km}^{2} 3 \mathrm{D}$ seismic data (Kribi-Campo basin) and $75 \mathrm{~km}$ 2D seismic data (Hoang Sa basin). Polygonal faults are widely developed in both passive margins and have relatively similar characteristics. These highly faulted intervals are up to c. $1000 \mathrm{~m}$, characterized by normal faults with a throw of 10-20 ms TWT and $100 \mathrm{~m}-1000 \mathrm{~m}$ spacing, displaying a polygonal pattern in the map view. Polygonal faults in the Kribi-Campo basin developed almost in the entire Cenozoic sequence mainly in two sets, one in deep section and one in shallow section whereas the Hoang Sa basin developed the polygonal fault only in the shallow section up to the seafloor corresponding to the Pliocene- Pleistocene sequence. In the Kribi-Campo basin, polygonal faults are developed extensively in the high gradient slope $\left(3.4^{\circ}\right)$ which is relatively rare in the low gradient slope $\left(0.7^{\circ}\right)$. Hoang Sa basin shows the widespread polygonal fault except for the area of canyon occurrence. The occurrence of thick and widespread polygonal fault formations associated with the low amplitude reflections suggests the interpretation of finegrained sediments, thus possibly great seal potential for the study areas.
\end{abstract}

Keywords: Polygonal faults; Wet Africa; Hoang Sa basin; Vietnam; Hydrocarbon potential

\section{Introduction}

Faults at small scale are referred to fracture which has several specific trends and can joints together (Baniyounis and Diabat, 2020). A group of extensional faults arranged in a polygonal structure and developed in one or several layers (layer bound) is defined as polygonal faults (Cartwright, 1994). A polygonal fault system consists of a series of normal faults at a small scale, throws from 10 to $100 \mathrm{~m}$, that are closely spaced (100-1000 m) (Cartwright and Dewhurst, 1998). The mechanism for polygonal fault formation was first suggested by the episodic over-pressured shale sediments leading to collapse of large areas (basin-scale) which were responsible for the distribution of the fault system (Henriet et al. 1991: Cartwright, 1994). Nevertheless, this hypothesis could not explain the polygonal network geometry of the fault system (Cartwright and Lonergan, 1996). The hypothesis has subsequently been revised with detailed mapping. According to these authors, the deformation is layer-bound, essentially radially isotropic, and there is no evidence for displacement transfer to basement structures. The good explanation for the apparent extension is due to the volumetric contraction of fine sediment during compactional dewatering. This response to fluid expulsion from the mud rock in early compaction. Polygonal faults are mainly found in fine-grained sediments. Besides, they also occur in much coarser

DOI: $\underline{10.46717 / i g j .54 .1 E .2 M s-2021-05-23 ~}$ 
sediments which are interbedded with the fine-grained intervals. However, they do not exist solely within the coarse-grained intervals (Lonergan and Cartwright, 1999). Polygonal fault distribution has been documented worldwide, mainly by 2D and 3D seismic data due to the large scale and geometry of the fault system is not suitable for a field-based approach (Cartwright and Dewhurst, 1998) (Fig. 1). They are mainly distributed in the passive margins predominantly in fine-grained sediment sequences such as clay or biogenic sediments, widespread up to areas of $>1$ million $\mathrm{km}^{2}$. Understanding the polygonal faults is important for hydrocarbon migration and sealing. Because they interact with adjacent reservoirs, driving post-depositional reservoir geometry, faulting may trigger and have great control on sand remobilization and injection during early burial (Lonergan and Cartwright, 1999). They might also control the early fluid flow migration on a regional scale (Henriet et al, 1991). According to Henriet et al. (1991), because polygonal faulting primarily occurs in fine-grained sediments, it may be an indicator for hydrocarbon source rocks at a depth required for catagenesis. Nevertheless, source rocks may have been deformed to a general hydraulic fracturing at an early stage of their compaction at the early burial. Therefore, when these fractured rocks reach to the depth required for catagenesis, it will have earlier migration than those which still have to be fractured.

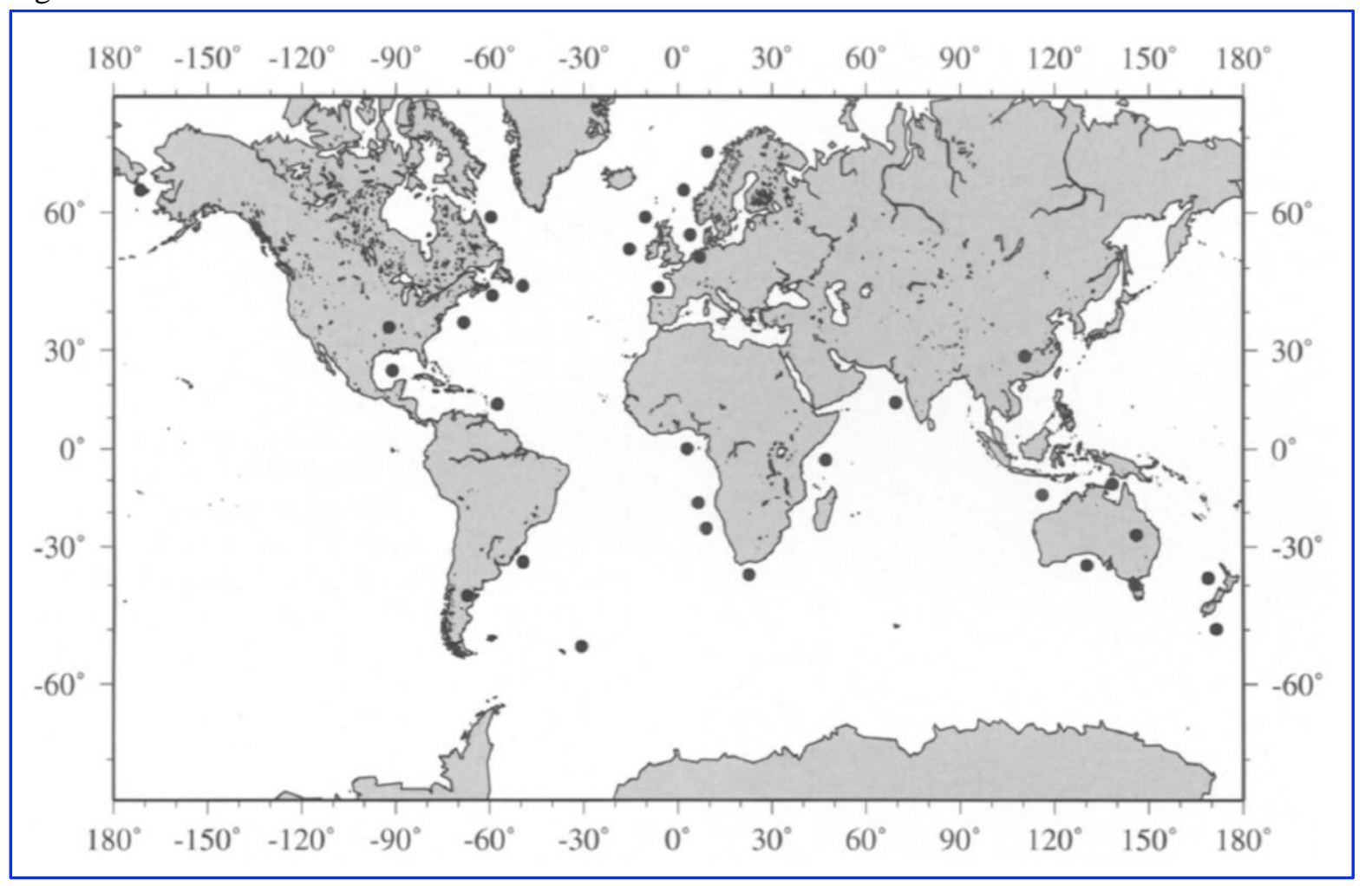

Fig. 1. Global distribution of polygonal faults systems detected from $2 \mathrm{D}$ and $3 \mathrm{D}$ seismic data with rarely field evidence. Polygonal faults are found dominantly in the passive margin or intra-cratonic settings, from Cartwright et al. (2003) adapted from Cartwright and Dewhurst (1998)

The presence of well-developed polygonal faults observed in newly 3D seismic data of West Africa, every stratigraphic sequence suggests the source and seal potential of the area. Polygonal faults possibly act as migration paths. Mapping and understanding of the polygonal fault occurrences have critical importance to evaluate the hydrocarbon potential and habitat of future exploration in the area. Due to the limitation of the data in the Hoang Sa basin, this study will present a detailed analysis case study in West Africa, then will extend the analysis of polygonal faults existence in the Hoang Sa basin, offshore Vietnam and its implications for oil and gas potential in Vietnam. 


\section{Regional setting}

\subsection{West Africa Area}

The study area covers an area of $1500 \mathrm{~km}^{2}$ and is located on the West Africa, continental slope. Modern-day seabed gradient is c. $3.4^{\circ}$ in the upper slope and c. $0.7^{\circ}$ in the lower slope. It lies within a water depth ranging from $600 \mathrm{~m}$ to $2000 \mathrm{~m}$. Based on the slope gradient and dipping direction, the area has been divided into high gradient slope area (HGS) and low gradient slope area (LGS). The HGS has slope angel of $1.6^{\circ}-3.4^{\circ}$, dipping westward; the LGS has slope angle of $0.7^{\circ}-2^{\circ}$, dipping southwest (Fig. 2). The study area is located in the Kribi-Campo sub-basin, one of several divergent margin basins on the West Africa continental margin. Those series of basins are formed during the breakup of Gondwana, as the result of progressively rifting from South to North of Africa and South America, starting in the Late Jurassic and lasting until the onset of seafloor spreading in Albian-Cenomanian time (Pauken, 1992). Rifting has been considered to start in the Kribi-Campo sub-basin from Barremian to Aptian time (Ntamak-Nida et al., 2010).

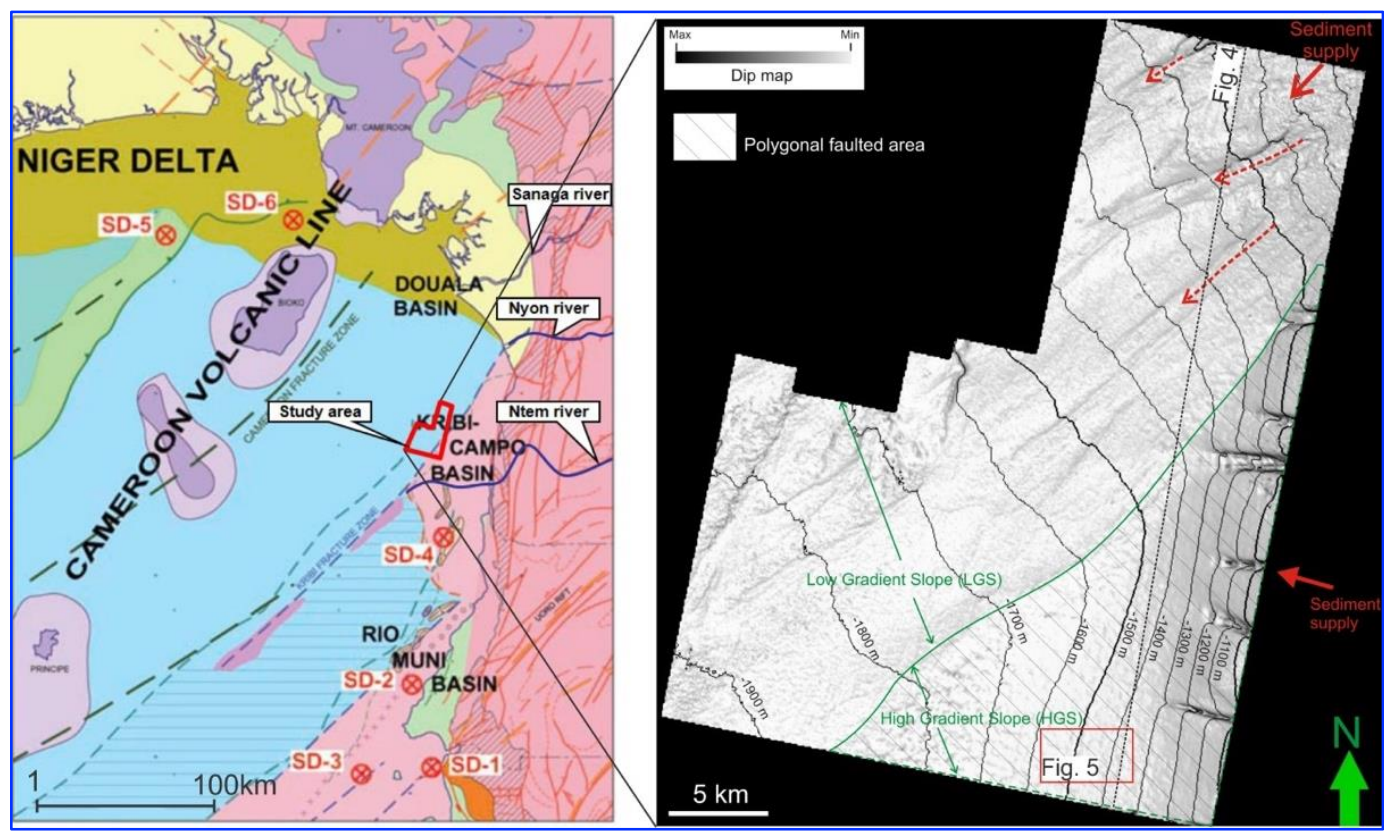

Fig. 2. The study area is located in the Kribi-Campo basin, offshore Cameroon (Lawrence et al. 2002). Seabed dip map of the study area (on the right) illustrating two defined slopes: west-dipping high gradient slope (HGS) and southwest-dipping low gradient slope (LGS)

\subsection{Hoang Sa basin, Offshore Vietnam}

Hoang Sa basin is located within $15^{\circ}$ to $17^{\circ} \mathrm{N}$ latitude and $109^{\circ} 30^{\prime}$ to $114^{\circ} \mathrm{E}$ longitude covering an area of c. $50,000 \mathrm{~km}^{2}$ (Fig. 3). Hoang Sa basin is a Northwest - Southeast extensional passive margin basin, characterized as a half-graben, formed in Cenozoic, up to $4.0 \mathrm{~s}$ TWT thick. The basin fill is characterized as continental facies to deep marine facies in the Middle Miocene to the present day. The basin evolution has two phases syn-rift and post-rift phase. Rifting commenced in the late Eocene and ended at the Late Oligocene. The thickness of the syn-rift sequence is c. 500-3000 m. The post-rift phase begins in the Early Miocene; the basin is a fully marine environment. 


\section{Materials and Methods}

The data used for this study comprises a high-resolution 3D seismic dataset, covering an area of $1500 \mathrm{~km}^{2}$ (Fig. 2). The Cenozoic stratigraphic succession of this study area is up to $3000 \mathrm{~ms}$ TWT. Due to the lack of well data in the basin, depth conversion assumes a similar lithological composition to the adjacent basins with a $\mathrm{Vp}$ velocity of $1850 \mathrm{~m} / \mathrm{s}$. This velocity and the calculated dominant frequency of $45 \mathrm{~Hz}$ in the Cenozoic give a vertical resolution $(\lambda / 4)$ of $\sim 10 \mathrm{~m}$. The seismic data is zero-phase and displayed in this study such as white or brown corresponds to positive polarity and black to negative polarity. The seismic interpretation has been performed using Petrel software 2013 with a fine interpretation grid. To analysis the lateral and vertical distribution of polygonal faults in the study area, the SVI Pro_64 edition software was applied by using the Fault Detect Application. The seismic cube will be run step by step from 1 seismic import, 2 faults enhanced, 3 fault detect, and 4 fault. This automatic fault mapping is the optimal method to justify areas that develop many faults. The data used for the Hoang Sa basin; offshore Vietnam is $75 \mathrm{~km}$ of 2D seismic line located in the western of the basin trending Northeast-Southwest. The study interval is about $2 \mathrm{~s}$ TWT below the seafloor (Fig. 3). Fault interpretation has been applied and then compared with the fault characteristics in the Kribi-Campo basin to see the similarity.

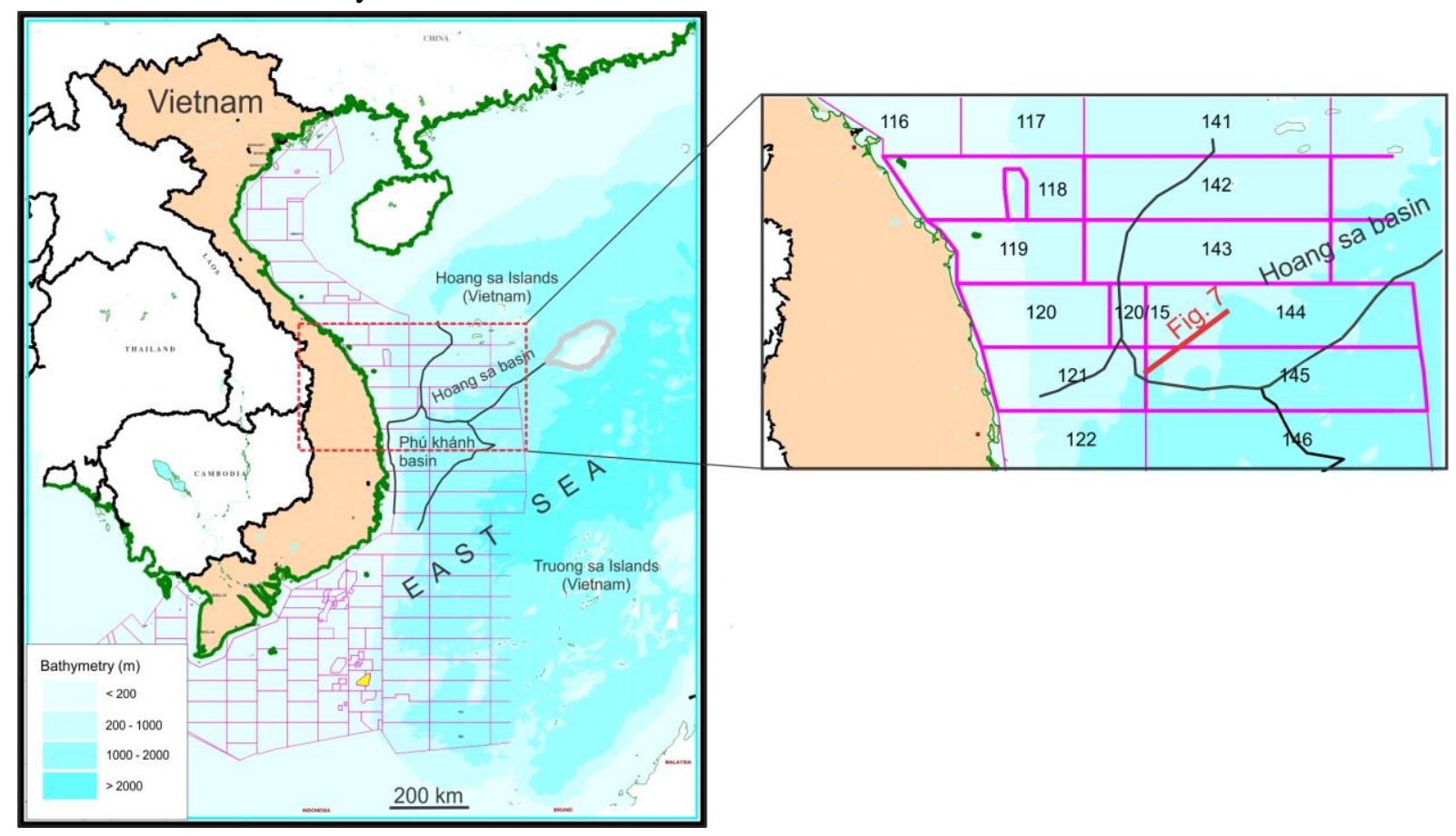

Fig. 3. A case study of Hoang Sa basin using 2D seismic data trending Northeast-Southwest located in Western of the Hoang Sa basin (Tran and Nguyen, 2009)

\section{Results}

\subsection{Stratigraphic Framework}

The Cenozoic deposits are predominantly characterized by sub-parallel, high amplitude reflections in the LGS and disrupted, low amplitude reflections in the HGS. The sequence is sub-divided into 7 seismic stratigraphic units, named unit 1 to unit 7, separated by 8 key surfaces labeled from KS_10 to the seafloor, defined by the combination of internal seismic reflection configuration, terminations, and the nature of the bounding surface (Fig. 4). The KS_10 surface forms the base of unit 1 and is characterized by a continuous, strong positive amplitude reflection, extending across the whole area. The surface is identified as a major unconformity with surfaces down lapping onto the erosional surface. 
KS_20 is the basal surface of unit 2, recognized as a week to strong positive amplitude reflection, disrupted by polygonal faults and extending across the whole study area. The surface marks a change from low amplitude reflection below to higher amplitude reflections above. KS_30, is the base of unit 3 and characterized by a strong negative reflection disrupted by polygonal faults in the southern area, especially on the HGS. The surface is the upper boundary of a high-density polygonal fault succession (Fig. 4), the base of polygonal faults being the KS_10 surface.

KS_40, is the base of unit 4 and identified as continuous, strong negative amplitude reflection. KS_50, is the basal surface of unit 5 and characterized by strong negative amplitude reflection with good continuity in the HGS and low and discontinuous in the LGS. KS_60, is the base of unit 6 and recognized as a very good, continuous, strong negative amplitude reflection. The surface is identified by bidirectional down lap above and is the base of the polygonal fault sequence in HGS. KS_70, the base of unit 7 , is identified as a weak to strong negative amplitude reflection. The surface marks the top boundary of the polygonal faults. Seabed is recognized as a continuous, strong positive amplitude reflection.
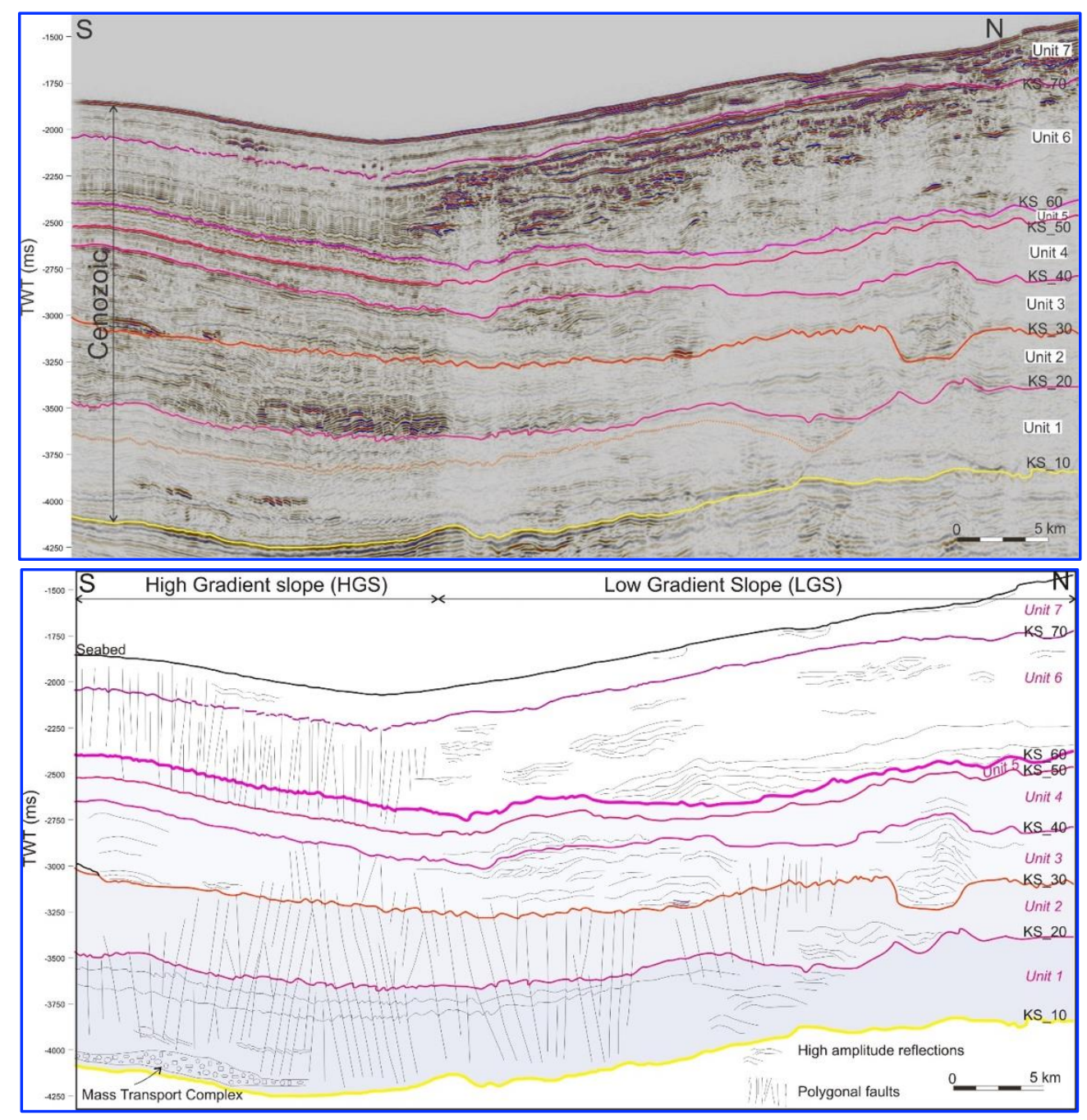

Fig. 4. A seismic line (above) and a line drawing of the seismic line (below) illustrate the observations and interpretation in each unit in Kribi-Campo basin. The study succession is bounded by the key surface KS_10 at the base and the seafloor at the top. Polygonal faults are prominently developed in the HGS at almost every stratigraphic level. 


\subsection{Polygonal Faults}

The seismic section trending North-South has illustrated the seismic key features investigated in the study area (Fig. 4). The high gradient slope is characterized by numerous closely spaced normal faults (100-1000 ms), small offset (10-20 ms) (Fig. 5). The faults are mainly dipping upslope or relatively vertical. This pattern has been identified throughout the high gradient slope area of dominantly low amplitude reflection, suggesting that the occurrence of these faults is possibly controlled by lithology. Low amplitude reflections are interpreted to be muddy sediments. According to the criteria of Cartwright and Dewhurst (1998), these faults are interpreted to be polygonal faults, resulting from lateral sediment contraction and pore fluid expulsion.

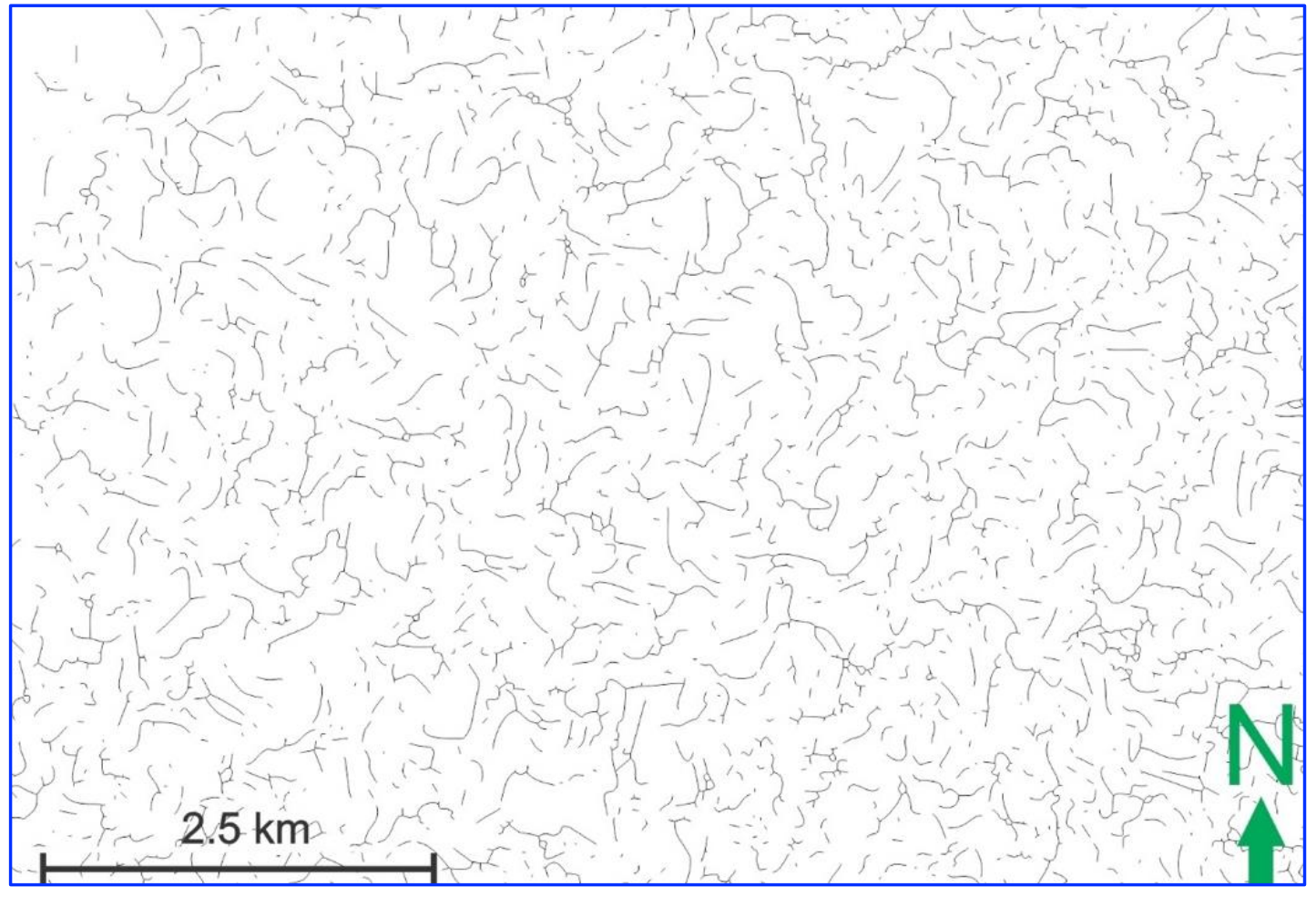

Fig. 5. The structural map of KS_70 reveals the highly faulted zone occurrence in the high gradient slope area of Kribi-Campo basin. They are mainly normal faults with closely spaced which is less than $700 \mathrm{~m}$, appearance dip upslope

The population and characterization of polygonal faults in the sediment column are investigated in more detail, using SVI Pro_64 edition software using the fault detect application over a selected dataset on the HGS. The results are shown in Fig. 6. In the map view, they have random orientation, disrupted every few hundred meters up to a kilometer. Maximum offsets are from 15 to $20 \mathrm{~m}$. This pattern has been identified throughout the study area and develops intensively in the HGS. Polygonal faults are detected in almost every stratigraphic succession except unit 4 (Fig. 6). Faults are more prominent in Unit 1, 2 and 5, 6; and are characterized by larger spacing and offset in the lower units compared with shallower. In the map view, faults show random orientation but are well connected. Their characteristics are similar to the observations of polygonal faults documented in the North Sea and Gabon (Cartwright and Dewhurst, 1998; Gay et al., 2004).

\subsection{Polygonal Faults in Hoang Sa Basin, Offshore Vietnam}

Polygonal faults have been observed in Pliocene-Pleistocene, western Hoang Sa basin. This sequence thickness is estimated at about 600-1000 m, consist of rich claystone, interbedded with silt, siltstone, sand, and sandstone, deposited in shallow and deep marine settings. Fault offsets are from 10 
to $20 \mathrm{~ms}$ TWT, spacing from a few hundred meters to a kilometer (Fig. 7). In the map, view the faults show the polygonal pattern (Tran and Nguyen, 2009). Polygonal faults are only observed in very shallow section reach the seafloor, where the sediment is dominant by mud rich. Polygonal faults are highly developed in the flanks of West Hoang Sa High. The fewer polygonal faults on the West Hoang Sa High are possibly caused by the strong modification of submarine canyons in this area.

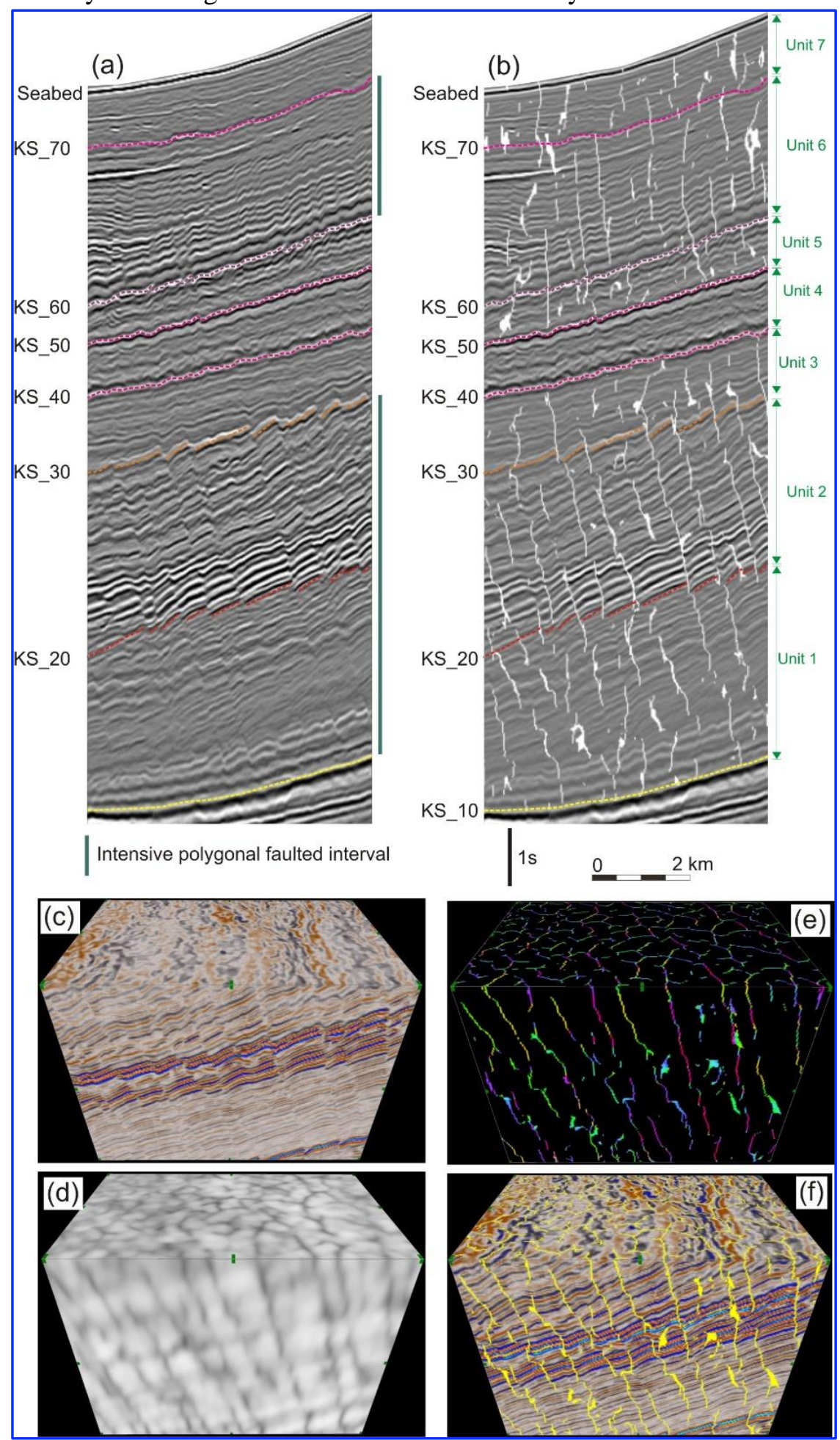

Fig. 6. (a) Un-interpreted selected seismic section of Cenozoic sequence in Kribi-Campo basin. (b) Faults detected using SVI Pro software. (c) - (f): 3D view showing processing in SVI pro from (c) seismic import, (d) fault enhanced using variance attribute, (e) fault detect, and (f) fault in. Faults are dominantly in units 1,2 and 5, unit 6 are closely spaced from every few hundred meters up to a 
kilometer. Maximum offsets are from 15 to $20 \mathrm{~m}$. They are well connected without any obvious trends and interpreted to be polygonal faults

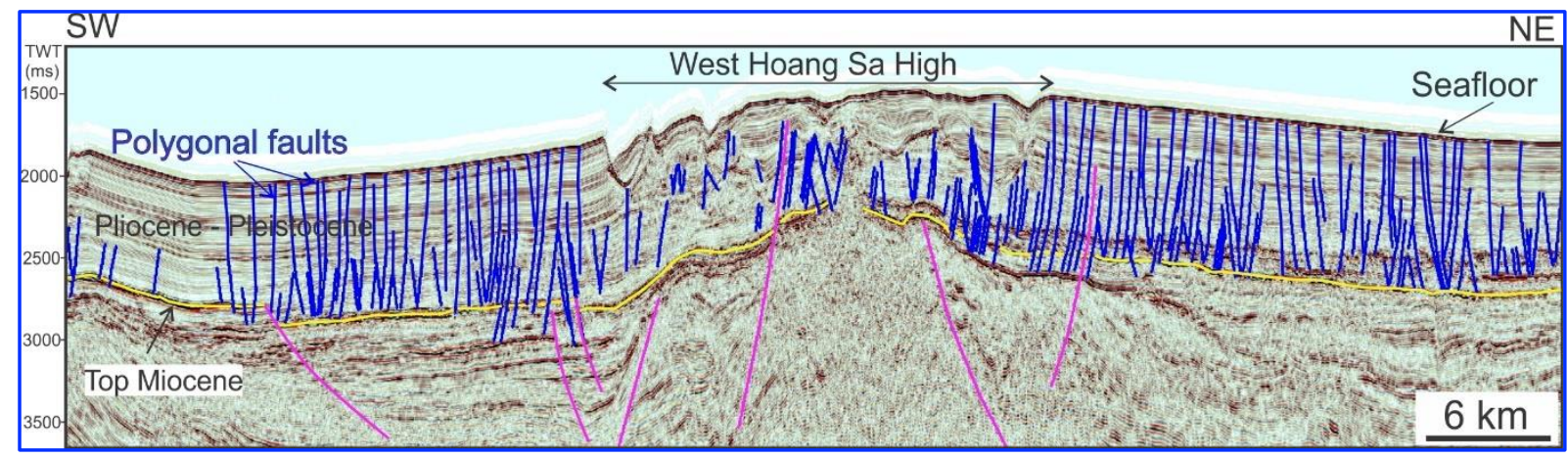

Fig. 7. A seismic section of Hoang Sa basin. Polygonal faults developed in the shallow section, up to the seafloor. They distributed extensively in the flanks of the uplift with the spacing from hundred meters to a kilometer

\section{Discussion}

\subsection{Polygonal Fault in West Africa}

Polygonal faults have been reported along the West Africa margin, offshore Angola (Gay et al. 2004), and offshore Namibia (Cartwright and Dewhurst, 1998)). In the study area, polygonal faults are the most common facies observed. It is prominent in the HGS, but less common in the LGS. The occurrence of polygonal faults and the dominance of low amplitude reflections in the HGS suggest prominently fine-grained sediment. Polygonal faults are different in scale, larger spacing and offset in the lower units compared with shallower. This is possibly related to the variation of grain size deposited during the basin evolution. High Gradient Slope sequences are possibly sealing potential units. However, the occurrence of polygonal faults needs to consider as they may affect seal integrity.

Polygonal faults are different from other faults as they are embedded within the ultralow permeability sealing sequences, thus may impact the seal quality (Cartwright et al. 2003). The polygonal faults occurred in low grain size which is normally considered as low permeability and seal potential. In the early stage of compaction and dewatering to form polygonal faults may still create significant potential permeability heterogeneity. Therefore, fluid flux may have occurred during the fault active slip (Sibson, 1981). Polygonal faults have been considered to be the main conduit for hydrocarbons leaking from reservoirs in the North Sea (Stuevold et al., 2003; Berndt et al., 2003) or have been inferred to be the fluid migration paths that are associated with the pockmark trails in Congo (Gay et al. 2004). These however are indirect evidence for fluid migration along polygonal fault planes.

The fact is that there are many hydrocarbon accumulations successfully trapped by a cap rock that is polygonal faulted, suggesting that fluid migration through these faults might be at a very slow rate. This is supported by the fact that there is no fault gouge in the polygonal fault planes and the permeability along the fault planes is generally lower than the host rocks, reviewed by Cartwright et al. (2007). In general, polygonal faults seal or unseal is still not clear, either considered as a main conduit for hydrocarbon leaking or as a seal. Good seal potential was observed in units 1,2,5 and 6 of the study areas. However, further studies will be needed to constrain better the seal integrity as where the channelfan deposits are present, which might enhance the vertical connectivity and leakage. The lack of polygonal faults in unit 4 is possibly indicated coarser-grained sedimentology of unit 4. Polygonal normally developed within a specific succession suggested the uniform lithology of the layer/layers, dominantly mudstone. 


\subsection{Polygonal Faults in Hoang Sa Basin, Offshore Vietnam}

The occurrence of polygonal faults in Hoang Sa basin shows similar characteristics to the ones occurring in West Africa and elsewhere. However, polygonal faults are only developed in very shallow section, Pliocene - Pleistocene, to the present day. The presence of polygonal faults indicated the occurrence of fine-grain sediment capping the entire area. This will give a great seal potential for the hydrocarbon trap in the area. There is no well data in the basin, thus, the petroleum system of the basin has been investigated based on few 2D seismic data in the area and geochemical results from the nearby basins (Tran and Nguyen, 2009). The results support a great hydrocarbon potential, and possibly gas as gas has been discovered in the eastern portion of the Song Hong basin which is adjacent to the Hoang Sa basin.

\section{Conclusions}

Polygonal faults have been documented in offshore Cameroon and Hoang Sa basin. They occur in the Cenozoic sequence and characterize as normal faults, closely spaced with a throw that varies from $10 \mathrm{~ms}$ to $20 \mathrm{~ms}$ TWT, space from $100 \mathrm{~m}$ to $1000 \mathrm{~m}$. In the map view, they have a polygonal expression, dipping upslope or relatively vertical. Polygonal faults have greater throw and spacing at depth. Polygonal faults are widely developed in both basins. In Kribi-Campo basin they prominently developed in the HGS dominated by low amplitude reflections, interpreted to be fine-grained sediments but rarely in LGS which are characterized by high amplitude reflections interpreted to be coarser grain. Similarly, in the Hoang Sa basin, polygonal faults developed in the flanks of the West Hoang Sa High dominated by low to high amplitude reflections corresponding to the fine-grained sediments but rarely in the West Hoang Sa High which is develop the sandy canyon system. The occurrence of polygonal faults in the study areas possibly provides great seal potential, however, further analysis needs to be done for a better understanding of the fluid migration and seal integrity. The results will give add to the knowledge of understanding polygonal fault occurrence and characteristics in West Africa continental margin and Vietnam continental margin and improve petroleum assessment for future drilling in this area.

\section{Acknowledgements}

I would like to thank Sterling Energy Company for providing the 3D seismic data of the Cameroon margin. I am very grateful to Schlumberger for software provided. I would like to express my gratitude to the reviewers for very useful and constructive comments for this paper. The author is very grateful to the Editor in Chief Prof. Dr. Salih M. Awadh, the Secretary of Journal Mr. Samir R. Hijab. and the Technical Editors for their great efforts and valuable comments.

\section{References}

Baniyounis, R. B., Diabat, A. A., 2020. Structural analysis of folds system and related meso structures in the area west of Irbed, Jordan. Iraqi Geological Journal, 53 (1D), 68-92.

Berndt, C., Bunz, S., Mienert, J., 2003. Polygonal fault systems on the mid-Norwegian margin: a long-term source for fluid flow. Geological Society, London, Special Publications, 216 (1), 283-290.

Bolton, A., Maltman, A., 1998. Fluid-flow pathways in actively deforming sediments: the role of pore fluid pressures and volume change. Marine and Petroleum Geology, 15, 281-297.

Cartwright, J., Huuse, M., Aplin, A., 2007. Seal bypass systems. AAPG bulletin, 91 (8), 1141-1166.

Cartwright, J., James, D., Bolton, A., 2003. The genesis of polygonal fault systems: a review. Geological Society, London, Special Publications, 216 (1), 223-243.

Cartwright, J. A., 1994. Episodic basin-wide fluid expulsion from geopressured shale sequences in the North Sea basin. Geology, 22 (5), 447-450.

Cartwright, J. A. Dewhurst, D. N., 1998. Layer-bound compaction faults in fine-grained sediments. Bulletin of the Geological Society of America, 110 (10), 1242-1257. 
Cartwright, J. A., Lonergan, L., 1996. Volumetric contraction during the compaction of mudrocks: a mechanism for the development of regional scale polygonal fault systems. Basin Research, 8 (2), 183-193.

Gay, A., Lopez, M., Cochonat, P., Sermondadaz, G., 2004. Polygonal faults-furrows system related to early stages of compaction-upper Miocene to recent sediments of the Lower Congo Basin. Basin Research, 16, 101116.

Henriet, J. P., De Batist, M., Verschuren, J., 1991. Early fracturing of Palaeogene clays, southernmost North Sea: relevance to mechanisms of primary hydrocarbon migration. In Spence, A. M (Ed.). Special publication of the European Association of Petroleum Geoscientists 1. Oxford University Press, Oxford, 254-264.

Lonergan, L., Cartwright, J. A., 1999. Polygonal faults and their influence on deep-water sandstone reservoir geometries, Alba Field United Kingdom Central North Sea. AAPG Bulletin, 83 (3), 410-432.

Lawrence, S. R., Munday, S., Bray, R., 2002. Regional geology and geophysics of the eastern Gulf of Guinea (Niger Delta to Rio Muni). The Leading Edge, 21, 1112.

Ntamak-Nida, M. J., Bourquin, S., Makong, J. C., Baudin, F., Mpesse, J. E., Christophe, I. N., Komguem, P. B., Abolo, G. M., 2010. Sedimentology and sequence stratigraphy from outcrops of the Kribi-Campo subbasin: Lower Mundeck Formation (Lower Cretaceous, southern Cameroon). Journal of African Earth Sciences, 58, 1-18.

Pauken, R. J., 1992. Sanaga sud field, offshore Cameroon, West Africa. In: Halbouty, M.J. (Ed.). Giant oil and gas field of the decade 1978-1988, Mobil exploration ventures Co Texas. AAPG Memoirs, 54, 217-230.

Sibson, R. H., 1981. Fluid flow accompanying faulting: field evidence and models. Maurice Ewing Series, 4, 593603.

Stuevold, L. M., Faerseth, R. B., Arnesen, L., Cartwright, J., Moller, N., 2003. Polygonal faults in the Ormen Lange Field, offshore Norway. IN Rensbergen, P. V., Hillis, R., Maltman, A. \& Morley, C. (Eds.) Subsurface sediment mobilisation. Geological Society, London, Special Publications, 216 (1), 263-281.

Tran, D. C., Nguyen, Q. H., 2009. Hoang Sa Sedimentary Basin and Petroleum Potential. In: Nguyen-Hiep (Ed). The Petroleum Geology and Resources of Vietnam. Science and Technics Publishing House, 552pp. 